\title{
Role of newer technologies in wound bed preparation in Fournier's gangrene
}

\author{
Souradeep Dutta, Abhinav Aggarwal, Ravi Kumar Chittoria, Elankumar Subbarayan, Vinayak Chavan, \\ Konda Sireesha Reddy, Saurabh Gupta, Chirra Likhitha Reddy
}

Department of Plastic Surgery, Jawaharlal Institute of Postgraduate Medical Education and Research, Pondicherry 605006, India.

\begin{abstract}
Correspondence to: Prof. Ravi Kumar Chittoria, Department of Plastic Surgery, Jawaharlal Institute of Postgraduate Medical Education and Research, Quarter number 7, Type V-A, Block no 4, Link Road, Pondicherry 605006, India. E-mail: drchittoria@yahoo.com
\end{abstract}

How to cite this article: Dutta S, Aggarwal A, Chittoria RK, Subbarayan E, Chavan V, Reddy KS, Gupta S, Reddy CL. Role of newer technologies in wound bed preparation in Fournier's gangrene. Plast Aesthet Res 2018;5:20.

http://dx.doi.org/10.20517/2347-9264.2018.19

Received: 3 Apr 2018 First Decision: 16 May 2018 Revised: 11 Jun 2018 Accepted: 11 Jun 2018 Published: 28 Jun 2018

Science Editor: Raúl González-García Copy Editor: Jun-Yao Li Production Editor: Huan-Liang Wu

\begin{abstract}
Fournier's gangrene or necrotizing fasciitis of the perineum scrotum and penis is a highly debilitating condition with a high mortality rate of $20 \%$ to $88 \%$ reported in the literature. Management is multimodal, and the importance of aggressive debridement, broad-spectrum antibiotics and intensive supportive care cannot be emphasised. The addition of newer modalities of ulcer/wound management like low level laser therapy, hydrojet debridement and platelet rich plasma can be used to augment the existing principles of management and reduce the morbidity and mortality associated with the condition. This article is the authors' experience with the condition and the above stated newer modalities in the management while staying true to the principles of management.
\end{abstract}

Keywords: Fournier's gangrene, low level laser therapy, platelet rich plasma, jet force technology, hydrojet debridement, wound bed preparation, insulin therapy

\section{INTRODUCTION}

Fournier's gangrene (FG) is a synergistic polymicrobial necrotizing fasciitis of the perineum, scrotum and penis which is characterized by obliterative endarteritis of the subcutaneous arteries, resulting in gangrene of the subcutaneous tissue and the overlying $\operatorname{skin}^{[1]}$. Jean Alfred Fournier ${ }^{[2]}$, a French dermatologist in 1883 was the first to describe a "fulminant gangrene" of the penis and scrotum that: (1) developed suddenly in previously healthy young men, (2) progressed rapidly, and (3) was idiopathic. The disease is no longer restricted to young men but may affect a wide age range from neonates to the very elderly. Since then this

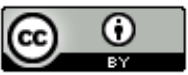

(c) The Author(s) 2018. Open Access This article is licensed under a Creative Commons Attribution 4.0 International License (https://creativecommons.org/licenses/by/4.0/), which permits unrestricted use, sharing, adaptation, distribution and reproduction in any medium or format, for any purpose, even commercially, as long as you give appropriate credit to the original author(s) and the source, provide a link to the Creative Commons license, and indicate if changes were made.

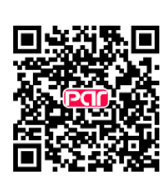




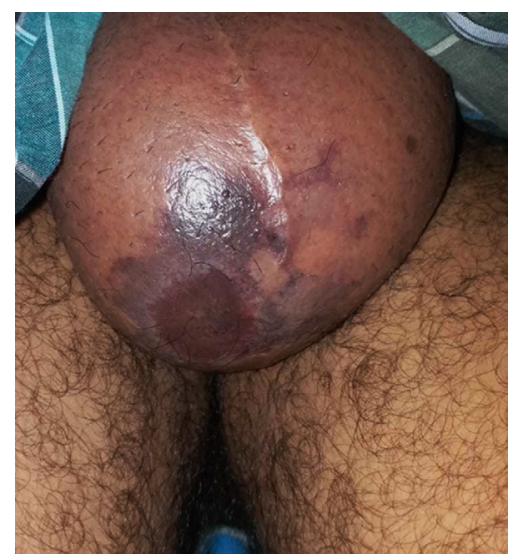

Figure 1. Swollen scrotum with necrotic patch on presentation

disease has been described in various nomenclatures in medical literature. Meleney ${ }^{[3]}$, a pioneer surgeonbacteriologist described a more generalized form of the disease and named it "streptococcus gangrene". In 1952, Wilson ${ }^{[4]}$ coined the term "necrotizing fasciitis".

FG extensively spreads to surrounding tissue and fascial layers, frequently resulting in septic shock and multiorgan failure. Standard treatment mainly includes surgical debridement of necrotic tissue and broadspectrum antibiotics. Several earlier studies have reported a mortality rate of $20 \%-88 \%$ in $\mathrm{FG}^{[5-7]}$. But recent studies suggest significantly lower mortality rates of $10 \%$ or less, likely due to due to better understanding of pathophysiology, availability of higher antibiotics and improved processes of care for these patients ${ }^{[8-11]}$. Despite lower mortality, patients with FG suffer from increased morbidity, including multi-organ system dysfunction, complex wound care, prolonged hospitalization and ongoing care needs beyond hospital discharge ${ }^{[12-14]}$.

We present here a case of 35-year-old male diagnosed with FG with extensive spread to the abdominal wall, septic shock requiring prolonged intensive care - a multidisciplinary management experience over 6 months with experiences of some newer investigational modalities of advanced wound management in the Department of Plastic Surgery like low level laser therapy, debridement with hydrojet, application of autologous platelet rich plasma, topical application of insulin on wound bed, phenytoin topical use on wound bed and use of collagen dressings. These modalities have been studied widely for improving the wound bed preparation of chronic wounds and are specifically useful in reducing the time needed for optimal wound bed preparation in a chronic illness like FG.

\section{CASE REPORT}

A 35-year-old married gentleman, resident of Tamil Nadu, a known alcoholic and tobacco chewer with no other known comorbid conditions, presented in surgical emergency of JIPMER on 26th of September 2017 with complaints of gradually progressive scrotal swelling for 3 days associated with redness, severe pain, and high-grade fever with chills and no history of any trauma. He had a history of perianal abscess for which incision and drainage was done in some other hospital one week back. On examination, he had an anxious look, dehydrated, with a temperature of $102.6 \mathrm{~F}$, tachycardia and hypotension. There was significant scrotal wall edema, erythema and blackish necrotic patches over the right hemi-scrotum [Figure 1]. The perineal region had the evidence of previous incision and drainage (I\&D) site which was unhealthy and filled with slough. The clinical findings were supplemented with an urgent ultrasonography of the perineal region and a diagnosis of FG was made and was planned for urgent debridement and exploration. Arterial blood gas (ABG) analysis showed a picture of compensated metabolic acidosis. Fournier's gangrene severity index (FGSI) score was 10 at the initial presentation, which inferred a mortality risk of more than $75 \%{ }^{[15]}$. 


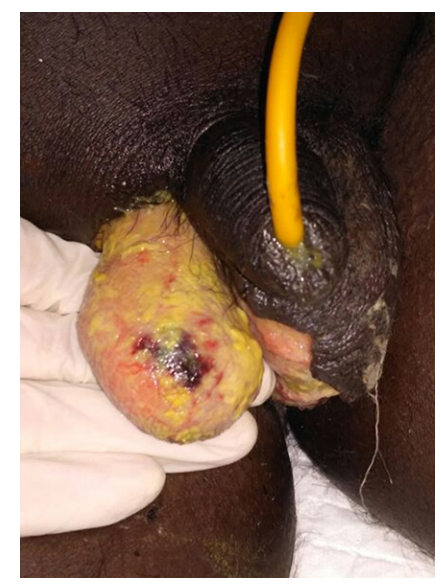

Figure 2. Right hemi testis after surgical debridement on day 17

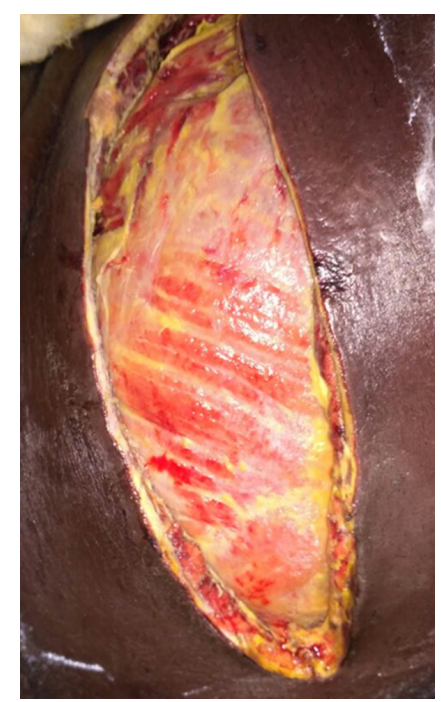

Figure 3. Raw area on abdomen after surgical debridement on day 17

The patient underwent debridement of the necrotic scrotal slough; exploration of the previous I\&D site and diversion sigmoid colostomy (to aid the healing of the perineal ulcer). Both the testis were healthy, and no extension of the infection was noted into other spaces. Immediate postoperative period was uneventful, and he was started on broad-spectrum antibiotics, and changed to culture based sensitive antibiotics subsequently.

On 7th post-operative day, he again developed fever spikes, with rapidly deteriorating ABG values. On further evaluation he was found to be in sepsis and was shifted to the Critical care unit of our institution. He was intubated and put under mechanical ventilation and administered noradrenaline support in view of falling blood pressures. Subsequently, he was found to be having tense abdominal wall and was suspected to be having spread of the Necrotizing soft tissue infection. On 10th post-operative day, he was taken to a repeat surgery, where three horizontal incisions were given on the right side of the abdominal wall. Thorough debridement was done, washes were given, and corrugated drains kept in place [Figures 2 and 3]. For the next two months, he underwent multiple debridements with daily washes followed by vacuum assisted closure in CCU along with sepsis management. During the critical care stay, he also underwent percutaneous endoscopic gastrostomy for improving the enteral nutrition and tracheostomy for prolonged 


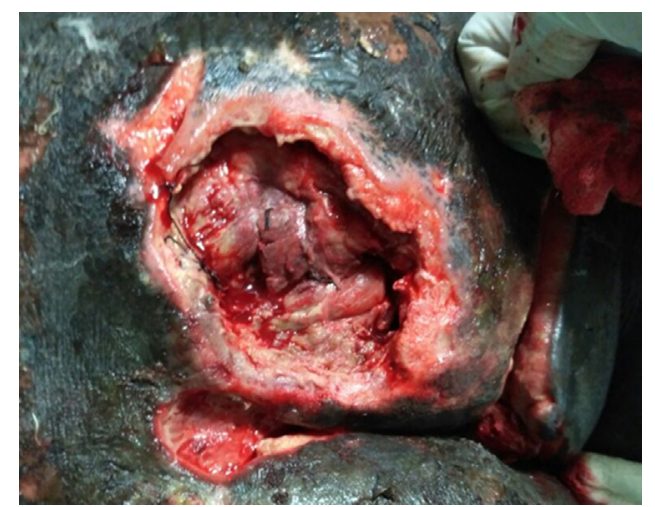

Figure 4. Bed sore after surgical debridement on day 17

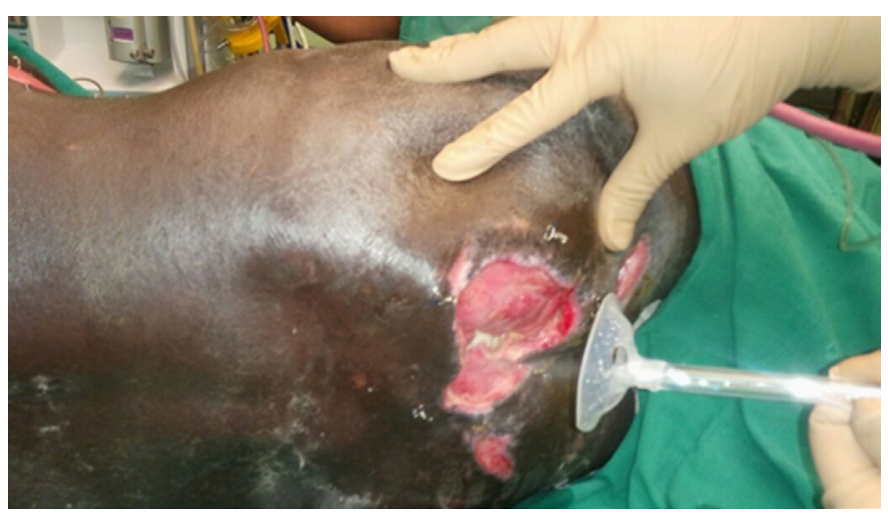

Figure 5. Bed sore debridement using hydrojet technology

ventilatory support. In the mean time, he developed a pressure ulcer on the sacral part [Figure 4], for which serial debridement and occlusive biological dressings and vacuum assisted closure were done. Gradually he recovered from sepsis and was weaned off from ventilator.

On day 25 the tracheostomy was closed and the patient was shifted to the Department of Plastic Surgery for advanced wound management for the raw areas that had developed after extensive debridement.

In the Department of Plastic Surgery, he underwent rigorous treatment of the FG and the bed sore with the novel techniques mentioned above.

Following surgical debridement, the patient was managed with debridement by hydrojet [Figure 5] every 2 to 3 days under local anesthesia plus low level laser therapy [Figure 6]. He also underwent regular autologous platelet rich plasma injections [Figure 7] and collagen dressings on the same days in the operating room. Topical insulin and phenytoin were used every time the dressing was done. Injection phenytoin $(50 \mathrm{mg} / \mathrm{mL})$ solution was diluted using normal saline $(0.9 \% \mathrm{NaCl})$ to prepare a phenytoin solution $(5 \mathrm{mg} / \mathrm{mL})$. Serum phenytoin concentration was monitored regularly in the Department of Clinical Pharmacology, JIPMER, and it was always below $0.4 \mu \mathrm{g} / \mathrm{mL}$, indicating only minuscule absorption of phenytoin following topical application. The patient did not report any local or systemic adverse event due to phenytoin during the treatment period.

Over a period of 20 days, patient condition improved drastically, and split skin grafting was done on day 21 following which patient improved and all post-surgical raw areas healed completely by day 49 [Figures 8-10]. 


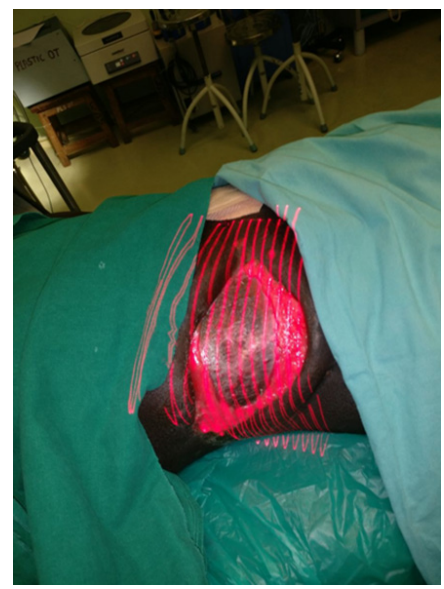

Figure 6. Low level laser therapy being given to abdomen raw area

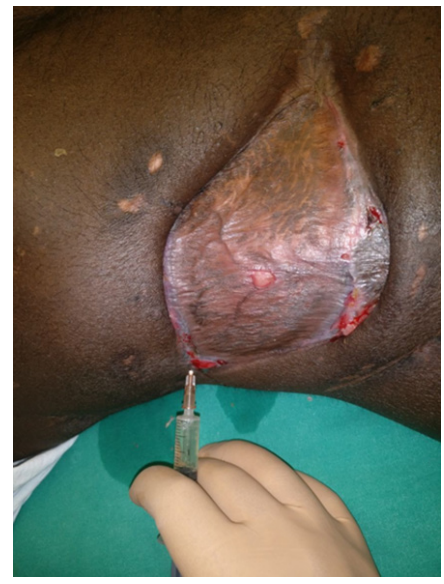

Figure 7. Autologous platelet rich plasma being injected in grafted raw area

\section{DISCUSSION}

The understanding of the aetiology and pathogenesis of FG has significantly become more evident since the condition was first described by Jean Alfred Fournier. Though the basis of good management is aggressive debridement, broad-spectrum antibiotics and intensive supportive care, there is significant amount of morbidity and increased hospital stay leading to skyrocketing treatment costs. Here comes the rationale of trying novel techniques like Low level laser therapy, hydrojet irrigation and autologous platelet rich plasma, which in our experience and opinion have significantly contributed in hastening the wound healing with decreased morbidity.

Low level laser therapy (LLLT) is a proven modality in the management of chronic infected wounds. Efficacy of LLLT in wound bed preparation was discovered by Mester et al. ${ }^{[16]}$ by application of a low-energy $\left(1 \mathrm{~J} / \mathrm{cm}^{2}\right)$ ruby laser. Unlike other medical lasers, LLLT does not have an ablative or thermal mechanism, but rather a photochemical effect in which the light is absorbed causing a chemical chang ${ }^{[17]}$. Multiple studies have proven LLLT to be very efficacious in improvement in chronic wounds, mostly diabetic foot ulcers ${ }^{[18-20]}$. But to the best of our knowledge, no studies or case reports on the use of LLLT in Fournier's Gangrene have been reported yet.

Autologous platelet rich plasma (APRP) has been reported to help in wound bed preparation in various aspects of medicine ${ }^{[21]}$. Platelets are known to express around 30 growth factors. They are chemotactic and 


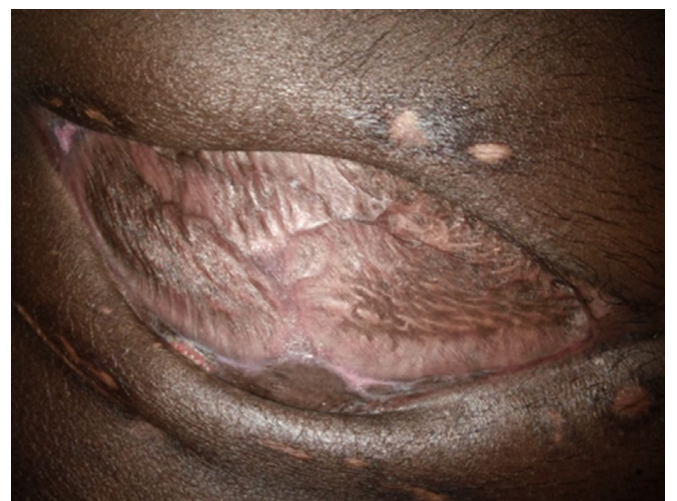

Figure 8. Healed abdomen wound

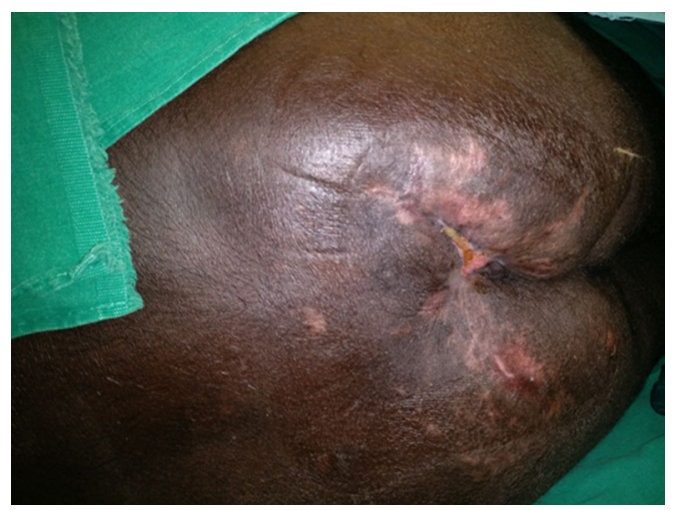

Figure 9. Healed sacral bed sore on day 49

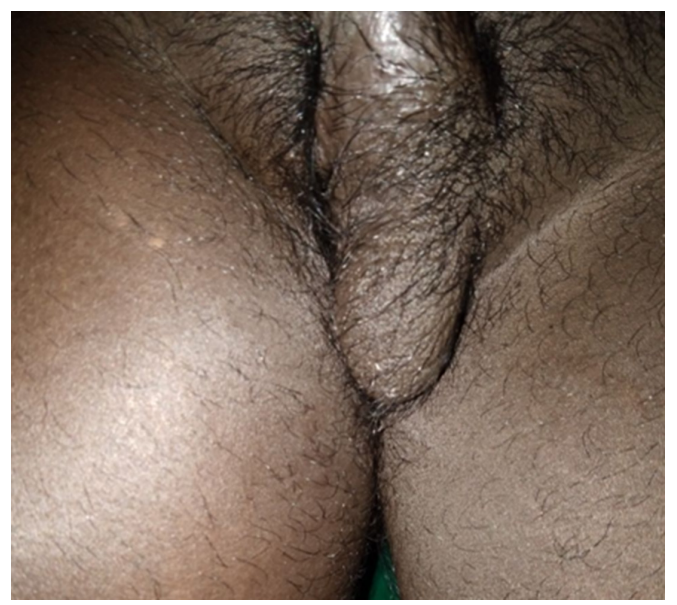

Figure 10. Healed groin wound

induce proliferation of fibroblasts, endothelial cells and similar precursor cells ${ }^{[22]}$, thus regulating the wound healing process. In various studies in our institute, APRP has been shown to be an effective tool to enhance healing in wound bed preparation of diabetic foot ${ }^{[23]}$, in chronic wound healing ${ }^{[24]}$ and many other similar indications. We have used our previous experience of using APRP in this case.

Hydrosurgical debridement is a novel modality, which enables the surgeon to precisely cut and remove nonviable tissue without causing collateral damage to healthy surrounding tissue using highly pressurized 
saline solution emitted from the tip of a hand-held instrument ${ }^{[25]}$. The jet travels through the nozzle of the instrument generating a Venturi effect which is an increase in the fluid's velocity and a decrease in its static pressure due to its passage through a constricted area ${ }^{[26]}$. Here, in this case, we have used jet force technology (JFT), which is a type of hydrotherapy previously studied extensively in our department and shown to be an effective means to debride the wounds without the mess of traditional methods and hasten wound healing ${ }^{[27]}$. It uses a disposable cannula, saline and oxygen under high pressure to mechanically remove the debris and bacteria, with addition of giving positive pressure oxygen therapy to the wound. Utilizing a unique triple nozzle, JFT is one of the simplest, most efficient and effective methods to do fast and virtually painless debridement when compared to other mechanical debridement methods.

Role of topical phenytoin in dental socket healing had been established since $1958^{[28]}$. Further studies have proven its efficacy in foot venous ulcers and diabetic foot wounds. The mechanism of action of topical phenytoin is still one of the mysteries of medical science. It has been postulated to cause a proliferation of human fibroblasts and keratinocytes while reducing the incidence of gram negative bacterial growth on the wound. Local pain relief has also been observed with topical phenytoin therapy, which can be explained by its membrane-stabilizing action. Systemic effects are not yet been reported with topical phenytoin application.

Topical Insulin therapy exerts its effects via IGF 1 receptor. Use of topical insulin in diabetic foot has shown to produce faster epithelization rates. Insulin has been known to stimulate keratinocytes and the rate of endothelial proliferation leading to faster neovascularization and formation of granulation tissue ${ }^{[2]}$.

These novel modalities are some very efficacious additives in this situation which can drastically reduce the burden and morbidity of a severely debilitating condition like FG with a very high rate of mortality. Efficacy of these modalities individually has been proven in modalities like burns, chronic wounds, diabetic foot ulcers in various studies.

As it is seen in this case report, the results achieved with these interventions together were astounding and further studies with a large sample size are needed to prove the same. The benefits of these interventions are that these are cost effective, innovative and easy to do in most centers around the world.

Hope our experience with this condition will promote innovation among the medical fraternity all over the world and efforts for more such novel modalities to get desired results.

In conclusion, FG is a serious surgical disease with a high mortality and morbidity. Early rehabilitation of a patient with Fournier's gangrene involves aggressive surgical intervention together with fluid, hemodynamic and nutritional support and broad-spectrum/targeted antibiotics, but a majority of the burden of hospital stay is wasted in wound bed preparation. This case emphasizes the importance of these simple, cost effective novel adjuncts like LLLT, APRP, hydrojet debridement, topical insulin and phenytoin therapy and the use of collagen dressing in accelerating wound bed preparation and decreasing the overall hospital stay and treatment costs.

\section{DECLARATIONS}

\section{Authors' contributions}

Concept and design: Dutta S, Chittoria RK

Data acquisition and analysis, manuscript preparation: Dutta S, Aggarwal A

Critical revision and finalizing of the manuscript: Chittoria RK, Subbarayan E, Chavan V, Reddy KS, Gupta S, Reddy CL 


\section{Availability of data and materials}

The data were strictly obtained from medical records according to the privacy policy and ethics code of our institute.

\section{Financial support and sponsorship}

None.

\section{Conflicts of interest}

All authors declared that there are no conflicts of interest.

\section{Ethical approval and consent to participate}

Due consent was taken from the patient to participate in the study and separately for the photography. Ethical approval was done according to the hospital and department policy.

\section{Consent for publication}

Not applicable.

\section{Copyright}

(c) The Author(s) 2018.

\section{REFERENCES}

1. Korkut M, Içöz G, Dayangaç M, Akgün E, Yeniay L, Erdoğan O, Cal C. Outcome analysis in patients with Fournier's gangrene: report of 45 cases. Dis Colon Rectum 2003;46:649-52.

2. Fournier JA. Jean-Alfred Fournier 1832-1914. Gangrène foudroyante de la verge (overwhelming gangrene). Sem Med 1883. Dis Colon Rectum 1988;31:984-8.

3. Meleney FL. Hemolytic streptococcus gangrene. Arch Surg 1924;9:317-64.

4. Wilson B. Necrotizing fasciitis. Am Surg 1952;18:416-31.

5. Eke N. Fournier's gangrene: a review of 1726 cases. Br J Surg 2000;87:718-28.

6. Yeniyol CO, Suelozgen T, Arslan M, Ayder AR. Fournier's gangrene: experience with 25 patients and use of Fournier's gangrene severity index score. Urology 2004;64:218-22.

7. Stone HH, Martin JD. Synergistic necrotizing cellulitis. Ann Surg 1972;175:702-11.

8. Basoglu M, Ozbey I, Atamanalp SS, Yildirgan MI, Aydinli B, Polat O, Ozturk G, Peker K, Onbas O, Oren D. Management of Fournier's gangrene: review of 45 cases. Surg Today 2007;37:558-63.

9. Sorensen MD, Krieger JN, Rivara FP, Broghammer JA, Klein MB, Mack CD, Wessells H. Fournier's gangrene: population based epidemiology and outcomes. J Urol 2009;181:2120-6.

10. Corcoran AT, Smaldone MC, Gibbons EP, Walsh TJ, Davies BJ. Validation of the Fournier's gangrene severity index in a large contemporary series. J Urol 2008;180:944-8.

11. Kim SY, Dupree JM, Le BV, Kim DY, Zhao LC, Kundu SD. A contemporary analysis of Fournier gangrene using the National Surgical Quality Improvement Program. Urology 2015;85:1052-6.

12. Ullah S, Khan M, Asad Ullah Jan M. Fournier's gangrene: a dreadful disease. Surgeon 2009;7:138-42.

13. Sorensen MD, Krieger JN, Rivara FP, Klein MB, Wessells H. Fournier's gangrene: management and mortality predictors in a population based study. J Urol 2009;182:2742-7.

14. Tahmaz L, Erdemir F, Kibar Y, Cosar A, Yalcýn O. Fournier's gangrene: report of thirty-three cases and a review of the literature. Int J Urol 2006;13:960-7.

15. Laor E, Palmer LS, Tolia BM, Reid RE, Winter HI. Outcome prediction in patients with Fournier's gangrene. J Urol 1995;154:89-92.

16. Mester E, Korényi-Both A, Spiry T, Tisza S. The effect of laser irradiation on the regeneration of muscle fibers (preliminary report). Z Exp Chir 1975;8:258-62.

17. Huang YY, Chen AC, Carroll JD, Hamblin MR. Biphasic dose response in low level light therapy. Dose Response 2009;7:358-83.

18. Kajagar BM, Godhi AS, Pandit A, Khatri S. Efficacy of low level laser therapy on wound healing in patients with chronic diabetic foot ulcers-a randomised control trial. Indian J Surg 2012;74:359-63.

19. Kaviani A, Djavid GE, Ataie-Fashtami L, Fateh M, Ghodsi M, Salami M, Zand N, Kashef N, Larijani B. A randomized clinical trial on the effect of low-level laser therapy on chronic diabetic foot wound healing: a preliminary report. Photomed Laser Surg 2011;29:109-14. 
20. Tchanque-Fossuo CN, Ho D, Dahle SE, Koo E, Li CS, Isseroff RR, Jagdeo J. A systematic review of low-level light therapy for treatment of diabetic foot ulcer. Wound Repair Regen 2016;24:418-26.

21. Everts PA, Knape JT, Weibrich G, Schönberger JP, Hoffmann J, Overdevest EP, Box HA, van Zundert A. Platelet-rich plasma and platelet gel: a review. J Extra Corpor Technol 2006;38:174-87.

22. Eppley BL, Woodell JE, Higgins J. Platelet quantification and growth factor analysis from platelet-rich plasma: implications for wound healing. Plast Reconstr Surg 2004;114:1502-8.

23. Chittoria R, Pandey S, Mohapatra DP, Friji MT, Dinesh KS. Role of autologous platelet rich plasma (APRP) in wound bed preparation (WBP) of diabetic foot ulcer (DFU). New Indian J Surg 2016;7:227-34.

24. Vijayaraghavan N, Mohapatra DP, Friji MT, S DK, Arjun A, Bibilash BS, Pandey S, Chittoria RK. Role of autologous platelet rich plasma (APRP) in wound healing. J Soc Wound Care Res 2014;7:23-8.

25. Hong CC, Nather A, Lee JKX, Mao HT. Hydrosurgery is effective for debridement of diabetic foot wounds. Ann Acad Med Singap 2014;43:395-9.

26. Wormald JCR, Wade RG, Dunne JA, Collins DP, Jain A. Hydrosurgical debridement versus conventional surgical debridement for acute partial-thickness burns (Protocol). Cochrane Database Syst Rev 2017;(10):CD012826.

27. Nandhagopal V, Chittoria RK, Mohapatra DP, Thiruvoth FM, Shivakumar DK, Ashokan A. Role of jet force technology in wound management. Plast Aesthet Res 2015;2:277-81.

28. Shapiro M. Acceleration of gingival wound healing in non-epileptic patients receiving diphenylhydantoin sodium (dilantin, epanutin). Exp Med Surg 1958;16:41-53.

29. Scimeca CL, Bharara M, Fisher TK, Kimbriel H, Mills JL, Armstrong DG. Novel use of insulin in continuous-instillation negative pressure wound therapy as "wound chemotherapy." J Diabetes Sci Technol 2010;4:820-4. 